\title{
Game Analysis of the Multiagent Evolution of Existing Building Green Retrofitting from the Perspective of Green Credit
}

\author{
Liwen Chen, Mengjia Zhang $(\mathbb{D}$, and Shiwen Zhao \\ School of Economics and Management, Hebei University of Technology, Tianjin 300401, China \\ Correspondence should be addressed to Mengjia Zhang; zmj07166@163.com
}

Received 20 February 2021; Accepted 2 June 2021; Published 16 June 2021

Academic Editor: Junhai Ma

Copyright (C) 2021 Liwen Chen et al. This is an open access article distributed under the Creative Commons Attribution License, which permits unrestricted use, distribution, and reproduction in any medium, provided the original work is properly cited.

\begin{abstract}
Existing building green retrofitting can reduce building energy consumption and greenhouse gas emissions, which is conducive to the sustainable development of the construction industry. The financing dilemma of the existing building green retrofitting hinders the large-scale development of green retrofitting in China. This paper establishes the perceived payoff matrix and evolutionary game model of the government, Energy Service Companies (ESCOs), banks, and owners. Through simulation analysis, the primary factors affecting the choice of game strategy and the stable strategy under different conditions are discussed. The results show that the strategic choices of the government, ESCOs, banks, and owners influence each other in the two game models. Government regulations will have an impact on the strategic choices of ESCOs, banks, and owners. The owners' strategy choice is closely related to the perceived benefits and costs of retrofitting. Based on the results, corresponding suggestions are proposed to provide theoretical support for the development of the existing building green retrofitting market.
\end{abstract}

\section{Introduction}

In recent years, environmental and energy issues related to the construction industry have become the focus of worldwide attention [1]. With the rapid urbanization process, the number of buildings in China has also increased. A large part of these buildings are high-energy-consuming buildings, leading to large amounts of energy consumption and carbon emissions. As a result, China's building energy consumption ranks second in the world, and its residential energy consumption ranks first [2]. This is not conducive to China's goal of achieving its carbon peak by 2030 and achieving carbon neutrality by $2060[3,4]$. The existing building green retrofitting is one of the main methods to reduce the energy consumption and carbon emissions of existing buildings [5]. It is generally accepted that green retrofitting can generate greater environmental benefits with lower costs and a higher utilization rate and thus achieve the sustainable development of the economy, society, and environment [6]. The Chinese government regards the existing building green retrofitting as an important energy policy and has adopted a series of measures to strenuously promote its development [7]. However, the implementation of green retrofitting requires a large amount of funds [8], and financing difficulties seriously hinder the implementation of this policy [9]. In particular, as one of the most important stakeholders in the market, energy service companies (ESCOs) are facing a financing dilemma that hinders the large-scale development of the existing building green retrofitting in China.

In China, bank credit is the most important external financing source for enterprises [10]. As an emerging industry, the scale of most ESCOs in China is still small, and they do not have strong financing capacities. Moreover, green retrofitting is generally not attractive to investors [11], which makes it difficult for ESCOs to obtain financing [12]. This is the key challenge to realizing the large-scale development of existing building green retrofitting [13]. The implementation of green credit policy provides new financing opportunities for ESCOs. However, the financial system is inherently complex [14], implementing green credit will result in incremental costs for banks and affect their financial performance, and the overall proportion of investment and loans to green projects by financial 
institutions is still low [15]. Therefore, green credit is still unable to play an effective role in the development of ESCOs.

In addition, existing studies on green credit mainly focus on the financing of the green supply chain [16], green technology innovation [17], and banks' performance [18]. There is little research on the impact of green credit implementation on ESCOs. Considering the current research status, this study explored the ESCO financing problem in green retrofitting and examined the influencing factors for the large-scale development of the green retrofitting market by constructing an interactive evolutionary game model of the government, ESCOs, banks, and existing building owners.

The remainder of the paper is structured as follows. The second part reviews the relevant literature and provides the main points of this paper. The third part proposes the corresponding hypotheses, constructs the three-party interactive evolutionary game model of the government, ESCOs, banks, and existing building owners, and analyzes it. The fourth part uses MATLAB to conduct the simulation analysis using the related data. The fifth part provides the conclusion and suggestions.

\section{Literature Review}

Green retrofitting is the retrofitting of existing buildings, including architectural design, components, and operations, to make existing buildings more environmentally friendly [19]. Although the implementation of green retrofitting is of great significance to improving environmental problems, the lack of funds has been a major obstacle to the implementation of retrofitting. In terms of financing barriers, the financing obstacles faced by green retrofitting include a lack of initial capital investment [20] and difficulty in obtaining loans or third-party financing for the ESCO industry in some countries [21]. In addition, Zhang et al. [13] found that, unlike other developing countries and emerging economies, more substantial obstacles do not exist at the system policy level, but at the meso- and microlevels of operation in China. Many scholars have conducted research on how to solve the financing problem of green retrofitting. Wang et al. [9] proposed a new financing principle model by improving the income-cost analysis method. Brown et al. [22] developed a housing retrofitting financing mechanism with the characteristics of capital sources and financial instruments. Liu et al. [7] found that the use of the EPC mode in building green retrofitting can solve the problems of insufficient funds and low efficiency in building retrofitting to a certain extent. He et al. [8] demonstrated through empirical research that the SEU financing mechanism can be an effective business model that supports building retrofitting. Economidou et al. [23] established a professional financing platform as an effective way to enhance the confidence of other participants. Guo et al. [24] analyzed the effectiveness evaluation content of the operation of the building energysaving retrofitting financing platform from the two levels of the operating mechanism and the behavior of the operating subject. Existing scholars have conducted in-depth research on how to solve the financing problem of green retrofitting.
However, most of these studies focus on financing models. Since green retrofitting involves multiple stakeholders, the coordination of interests between the participants is the key to improving financing. Therefore, analyzing the behavioral decisions of each participant in different situations is helpful in obtaining the best behavioral decision to balance the interests of all participants.

The evolutionary game provides an effective method for studying behavioral decision making. Evolutionary game theory is based on bounded rationality with groups as the research objects. It is believed that individual decision making is realized in the dynamic process of imitation, learning, and mutation [25]. Some scholars have used evolutionary games to study the related issues of the existing building green retrofitting. Liang et al. [26] analyzed three usage scenarios through evolutionary games and clarified the reasons why direct decision makers are unwilling to participate in green retrofitting projects. Liu et al. [27] established a cooperative game model and discussed the difference between noncooperative scenes and cooperative scenes and the influence of the parameters in the model. Through evolutionary game analysis, Yang et al. [28] revealed the game strategy changes in government groups and investment groups to encourage and implement green retrofitting.

Compared with the traditional classical game, the evolutionary game considers the bounded rationality of the decision maker, but it still objectively constructs the income matrix and analyzes it based on the classical expected utility theory [29]. Therefore, this paper introduces prospect theory to improve the credibility of evolutionary games and the effectiveness of the interpretation of reality. Prospect theory addresses the lack of rationality and considers the preferences of decision makers. It believes that people's decisions and choices depend on the difference between results and expectations rather than the results themselves. Because it measures the value of prospects under dynamic uncertain conditions, it is more in line with people's decision-making behavior in real situations [30]. The combination of prospect theory and evolutionary games has been used in the research of actors in the fields of financial supervision [31], construction waste recycling [11], and prefabricated buildings [30]. Green retrofitting projects are one of the most complex and risky types of projects, because there are relatively more stakeholders involved [9]. The behavioral decisions of the subjects involved in green retrofitting are actually risk decisions, and the selection of their behavioral strategies is based on the subjects' own subjective perceptions of the value of the strategy rather than the actual utility obtained. Therefore, from the perspective of green credit, this paper proposes an evolutionary game model of the government, ESCOs, banks, and existing building owners based on prospect theory.

In summary, although existing research has devoted more attention to the issue of retrofitting financing, there is a lack of research on the behavior and decision making of the major participants related to green retrofitting financing. Therefore, this paper combines prospect theory and evolutionary game theory to establish a more realistic 
interaction evolutionary game model of the government, ESCOs, banks, and existing building owners from the perspective of green credit and explores the different situations of each participant's strategic choice. The results enrich the research on the participants' strategic choice in the field of the existing building green retrofitting.

\section{Formulation of the Model}

The government, ESCOs, banks, and owners of existing buildings are all participants and promoters of the market for the existing building green retrofitting. By regulating other entities, the government encourages ESCOs, banks, and owners to participate in the existing building green retrofitting market [32]. By implementing green credit, banks provide loans to ESCOs, reduce the financing costs of ESCOs, and ease financing difficulties. ESCOs are the main implementer of green retrofitting. The owners of existing buildings are the demanders of green retrofitting. Based on the above relationship, the relationship diagram of the government, ESCOs, banks, and owners is shown in Figure 1.

\subsection{Basic Assumptions}

Hypothesis 1. The government, ESCOs, banks, and owners are the participants in the game model; and they are all bounded rational $[33,34]$. Information asymmetry exists among the four participants, and their decisions are influenced by their own preferences and the degree of information mastery. The gains and losses that need to be judged according to the decisions of other players are called the perceived gains and perceived losses, respectively. According to prospect theory, an individual's psychological feeling of strategy gain and loss is expressed by the perceived value $V$, and $V$ is calculated according to the value function $V(x)$ and the weight function $\pi(p)$ of prospect theory:

$$
\left\{\begin{array}{l}
v=\sum_{i} \pi\left(p_{i}\right) U\left(\Delta x_{i}\right), \\
U_{(x)}= \begin{cases}x^{\alpha}, & x \geq 0, \\
-\lambda(-x)^{\beta}, & x<0,\end{cases}
\end{array}\right.
$$

where $P_{i}$ is the objective probability of the occurrence of event $i ; \pi\left(P_{i}\right)$ is the decision weight, where $\pi(0)=0$ and $\pi(1)=1 ; \Delta x i$ is the deviation between the actual income obtained by participants and the reference point after the occurrence of event $i$, where $\Delta x i=x i-x 0$; parameter $\alpha$ is the risk preference coefficient; and $\beta$ is the risk aversion coefficient, which determines the degree of risk preference of the subject. $\alpha=\beta=1$ represents risk neutrality.

Hypothesis 2. In the model, each participant has two strategies to choose. The government can choose a "regulation" or "no regulation" strategy; and the policy set is $G=\left(G_{1}, G_{2}\right)$, which will be chosen for implementation in order to achieve environmental goals and improve political performance by promoting green retrofitting. If the regulatory costs are too high, this will cause the government to abandon regulation. The probability that the government chooses to regulate is $x(0 \leq x \leq 1)$, and the probability that it chooses not to regulate is $1-x$. Undertaking retrofitting can enhance the reputation of ESCOs and fulfill the social responsibility of enterprises. However, if the risk, costs, and benefit payback period of retrofitting is too high, ESCOs will be forced to give up green retrofitting. ESCOs can choose to "undertake retrofitting" or "not undertake retrofit," and the policy set is $C=\left(C_{1}, C_{2}\right)$. The probability of choosing to undertake green retrofitting is $y(0 \leq y \leq 1)$, and the probability of not undertaking retrofitting is $1-y$. The implementation of green credit can make banks better comply with national policies but may adversely affect the performance of banks. Therefore, banks can choose to "implement" or "not implement" strategies. The policy set is $B=\left(B_{1}, B_{2}\right)$. The probability that banks choose to implement green credit is $z(0 \leq z \leq 1)$, and the probability that they do not implement green credit is $1-z$. Existing building owners can benefit from energy conservation by conducting green retrofitting, but they need to pay the corresponding costs. The policy set is $O=\left(O_{1}, O_{2}\right)$. The probability of owners conducting retrofitting is $r(0 \leq r \leq 1)$, and the probability of owners not conducting retrofitting is $1-r$.

Hypothesis 3. When the government implements regulation, the perceived benefit of the government is $V_{1}$ and the regulatory cost is $C_{1}$. The fiscal subsidy that ESCOs can obtain when undertaking green retrofitting is $\beta_{1} C_{2}$, and the extra tax that should be paid when not undertaking it is $M$. When banks implement green credit, the subsidy they receive is $\beta_{2} I$; and when they do not implement green credit, the penalty they suffer is $\omega I$. When owners conduct retrofitting, the government gives the owners a subsidy of $B$. When the government does not implement regulation, the perceived benefit is $V_{2}$. If ESCOs do not undertake retrofitting, green retrofitting projects cannot be promoted normally, which will cause a decrease in the government's credibility. At this time, the perceived loss of the government is $S_{1}$.

Hypothesis 4. When ESCOs undertake green retrofitting, the perceived benefit is $V_{3}$ and the cost is $C_{2}$. When ESCOs do not undertake green retrofitting, the perceived benefit is $V_{4}$ and the cost is $C_{3}$. When ESCOs do not undertake green retrofitting, banks implement green credit, and owners conduct retrofitting, or ESCOs undertake green retrofitting, but owners do not conduct retrofitting, ESCOs will cause perceived loss $S_{2}$.

Hypothesis 5. When banks implement green credit, their perceived benefit is $V_{5}$ and their cost is $C_{4}$. When banks do not implement green credit, the perceived benefit is $V_{6}$ and the cost is $C_{5}$. When ESCOs undertake green retrofitting, but banks do not implement green credit, the banks' reputation will be affected. At this time, the perceived loss is $S_{3}$.

Hypothesis 6. When owners conduct retrofitting, their perceived benefit is $V_{7}$, and the cost they need to pay is $C_{6}$. 


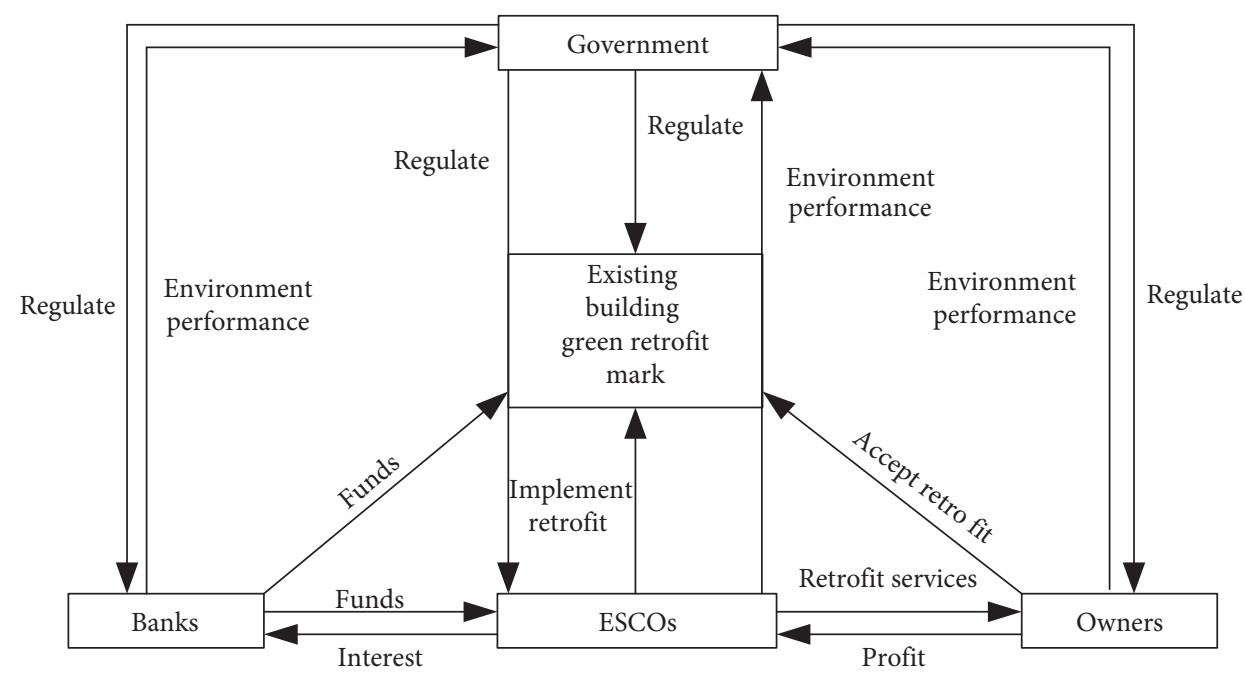

FIGURE 1: Relationship of the government, ESCOs, banks, and owners.

When the energy-saving income after retrofit fails to meet the expectation of owners, the perceived loss is $S_{4}$.

\subsection{Construction of the Evolutionary Game Model. Based on} the above assumptions, this paper constructs the payoff matrix of the two evolutionary game models shown in Tables 1 and 2 .

In the model, since the cost and subsidy for each agent to choose each strategy are predictable, it is a definite value. The gains and losses that need to be judged according to the decisions of other players are called perceived gains and perceived losses:

(1) When the government implements regulations, ESCOs, banks, and owners all choose green behavior; and the probability of the successful promotion of the retrofit project is $p_{1}=1$. In this case, the actual income obtained by the government, ESCOs, banks, and owners is $r_{1}, r_{2}, r_{3}$, and $r_{4}$, respectively. Then,

$$
\left\{\begin{array}{l}
V_{1}=\pi\left(p_{1}\right) v\left(r_{1}\right)+\pi\left(1-p_{1}\right) v(0)=\pi\left(p_{1}\right) v\left(r_{1}\right), \\
V_{3}=\pi\left(p_{1}\right) v\left(r_{2}\right)+\pi\left(1-p_{1}\right) v(0)=\pi\left(p_{1}\right) v\left(r_{2}\right), \\
V_{5}=\pi\left(p_{1}\right) v\left(r_{3}\right)+\pi\left(1-p_{1}\right) v(0)=\pi\left(p_{1}\right) v\left(r_{3}\right), \\
V_{7}=\pi\left(p_{1}\right) v\left(r_{4}\right)+\pi\left(1-p_{1}\right) v(0)=\pi\left(p_{1}\right) v\left(r_{4}\right) .
\end{array}\right.
$$

(2) When the government does not implement regulations and ESCOs, banks and owners do not choose green behavior, the probability $p_{2}=1$ that the retrofit project cannot be promoted results in the actual profits obtained by ESCOs, banks, and owners being $r_{5}, r_{6}$, and $r_{7}$, and the credibility loss suffered by the government due to its failure to adopt environmentally friendly behavior is $s_{1}$ :

$\left\{\begin{array}{l}V_{2}=\pi\left(p_{2}\right) v\left(r_{5}\right)+\pi\left(1-p_{2}\right) v(0)=\pi\left(p_{2}\right) v\left(r_{5}\right) \\ V_{4}=\pi\left(p_{2}\right) v\left(r_{6}\right)+\pi\left(1-p_{2}\right) v(0)=\pi\left(p_{2}\right) v\left(r_{6}\right) \\ V_{6}=\pi\left(p_{2}\right) v\left(r_{7}\right)+\pi\left(1-p_{2}\right) v(0)=\pi\left(p_{2}\right) v\left(r_{7}\right) \\ S_{1}=\pi\left(p_{2}\right) v\left(s_{1}\right)+\pi\left(1-p_{2}\right) v(0)=\pi\left(p_{2}\right) v\left(s_{1}\right)\end{array}\right.$

(3) In other cases, the probability of project implementation failure is $p_{3}$; therefore, the actual losses of ESCOs, banks, and owners are $s_{2}, s_{3}$, and $s_{4}$, respectively. Thus,

$$
\left\{\begin{array}{l}
S_{2}=\pi\left(p_{3}\right) v\left(s_{2}\right)+\pi\left(1-p_{3}\right) v(0)=\pi\left(p_{3}\right) v\left(s_{2}\right), \\
S_{3}=\pi\left(p_{3}\right) v\left(s_{3}\right)+\pi\left(1-p_{3}\right) v(0)=\pi\left(p_{3}\right) v\left(s_{3}\right), \\
S_{4}=\pi\left(p_{3}\right) v\left(s_{4}\right)+\pi\left(1-p_{3}\right) v(0)=\pi\left(p_{3}\right) v\left(s_{4}\right) .
\end{array}\right.
$$

\subsection{Stability Analysis of Government-ESCOs-Banks Equilibrium}

3.3.1. Analysis of Government's Strategy Selection. As Table 1 shows, the expected perceived values $U_{G 1}$ when the government chooses the regulation strategy and $U_{G 2}$ when the government chooses the no regulation strategy are, respectively, 
TABLE 1: Government, ESCOs, and banks perceived payoff matrix.

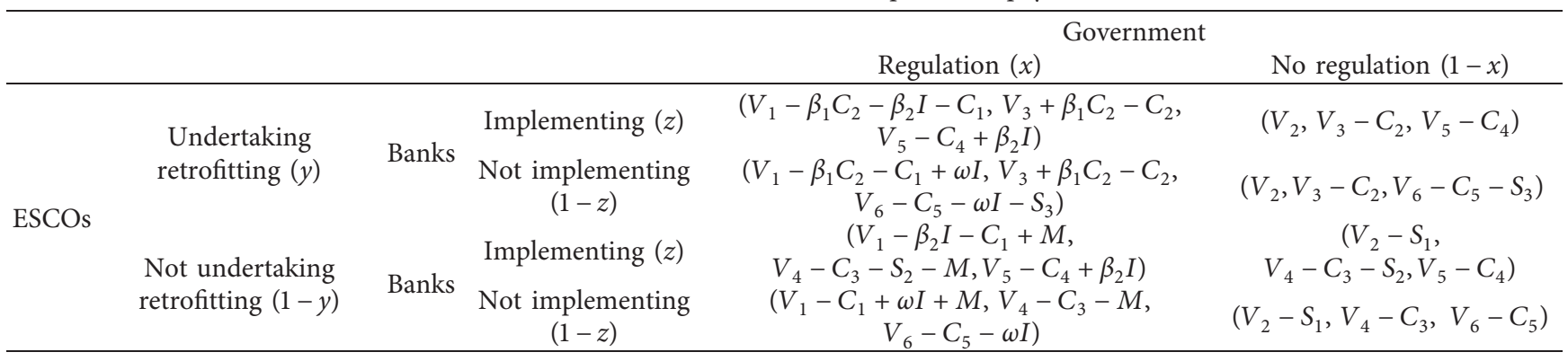

TABLE 2: Government, ESCOs, and owners perceived payoff matrix.

\begin{tabular}{|c|c|c|c|c|c|}
\hline & & & & \multicolumn{2}{|l|}{ Government } \\
\hline & & & & Regulation $(x)$ & No regulation $(1-x)$ \\
\hline \multirow{4}{*}{ ESCOs } & \multirow{2}{*}{$\begin{array}{l}\text { Undertaking retrofitting } \\
\qquad(y)\end{array}$} & \multirow{2}{*}{ Owners } & $\begin{array}{l}\text { Conducting retrofitting } \\
\qquad(r)\end{array}$ & $\begin{array}{c}\left(V_{1}-\beta_{1} C_{2}-B-C_{1}, V_{3}+\beta_{1} C_{2}-C_{2}\right. \\
\left.V_{7}+B-C_{6}\right)\end{array}$ & $\left(V_{2}, V_{3}-C_{2}, V_{7}-C_{6}\right)$ \\
\hline & & & $\begin{array}{l}\text { Not conducting } \\
\text { retrofitting }(1-r)\end{array}$ & $\left(V_{1}-C_{1}, V_{3}-C_{2}-S_{2}, 0\right)$ & $\left(V_{2}, V_{3}-C_{2}-S_{2}, 0\right)$ \\
\hline & \multirow{2}{*}{$\begin{array}{l}\text { Not undertaking } \\
\text { retrofitting }(1-y)\end{array}$} & \multirow{2}{*}{ Owners } & $\begin{array}{l}\text { Conducting retrofitting } \\
(r)\end{array}$ & $\begin{array}{c}V_{1}-C_{1}+M, V_{4}-C_{3}-M-S_{2} \\
\left.V_{7}-C_{6}-S_{4}\right)\end{array}$ & $\begin{array}{c}\left(V_{2}-S_{1}, V_{4}-C_{3}-S_{2}\right. \\
\left.V_{7}-C_{6}-S_{4}\right)\end{array}$ \\
\hline & & & $\begin{array}{l}\text { Not conducting } \\
\text { retrofitting }(1-r)\end{array}$ & $\left(V_{1}-C_{1}, V_{4}-C_{3}, 0\right)$ & $\left(V_{2}-S_{1}, V_{4}-C_{3}, 0\right)$ \\
\hline
\end{tabular}

$$
\begin{aligned}
U_{G 1}= & y z\left(V_{1}-\beta_{1} C_{2}-\beta_{2} I-C_{1}\right)+y(1-z)\left(V_{1}-C_{1}-\beta_{1} C_{2}+w I\right)+z(1-y)\left(V_{1}-C_{1}-\beta_{2} I+M\right) \\
& +(1-z)(1-y)\left(V_{1}-C_{1}+w I+M\right), \\
U_{G 2}= & y z V_{2}+y(1-z) V_{2}+z(1-y)\left(V_{2}-S_{1}\right)+(1-z)(1-y)\left(V_{2}-S_{1}\right) .
\end{aligned}
$$

The average expected perceived value of government $U_{G}$ is as follows:

$$
\begin{aligned}
U_{G}= & x U_{G 1}+(1-x) U_{G 2} \\
= & x\left[y z\left(V_{1}-\beta_{1} C_{2}-\beta_{2} I-C_{1}\right)+y(1-z)\left(V_{1}-C_{1}-\beta_{1} C_{2}+w I\right)+z(1-y)\left(V_{1}-C_{1}-\beta_{2} I+M\right)\right. \\
& \left.+(1-z)(1-y)\left(V_{1}-C_{1}+w I+M\right)\right] \\
& +(1-x)\left[y z V_{2}+y(1-z) V_{2}+z(1-y)\left(V_{2}-S_{1}\right)+(1-z)(1-y)\left(V_{2}-S_{1}\right)\right] .
\end{aligned}
$$

The government's replication dynamic equation is as follows:

$$
F_{1}(x)=\frac{\mathrm{d} x}{\mathrm{~d} t}=x\left(U_{G 1}-U_{G}\right)=x(1-x)\left[y\left(-\beta_{1} C_{2}-M-S_{1}\right)+z\left(-\beta_{2} I-w I\right)+V_{1}-C_{1}-V_{2}+S_{1}+M+w I\right]
$$

The derivative with respect to $F_{1}(x)$ is as follows:

$$
F_{1}^{\prime}(x)=\frac{\mathrm{d} F(x)}{\mathrm{d} x}=(1-2 x)\left[y\left(-\beta_{1} C_{2}-M-S_{1}\right)+z\left(-\beta_{1} I-w I\right)+V_{1}-C_{1}-V_{2}+S_{1}+M+w I\right]
$$


Let $F_{1}(X)=0$. Then, the stabilization strategy point of the government is $x_{1}=0, x_{2}=1$, and $z_{0}=y\left(-\beta_{1} C_{2}-M-\right.$ $\left.S_{1}\right)+V_{1}-C_{1}-V_{2}+S_{1}+M+w I / \beta_{1} I+w I$ and the discussion can be divided into three situations:

(1) If $z=z_{0}$, then $F_{1}(X)=0$. At this point, regardless of the value of $x$, there is a stable state. This indicates that when the probability of banks implementing green credit is $y\left(-\beta_{1} C_{2}-M-S_{1}\right)+V_{1}-C_{1}-$ $V_{2}+S_{1}+M+w I / \beta_{1} I+w I$, the government chooses the "regulation" or "no regulation" strategy to obtain equal benefits.

(2) If $z<z_{0}=y\left(-\beta_{1} C_{2}-M-S_{1}\right)+V_{1}-C_{1}-V_{2}+$ $S_{1}+M+w I / \beta_{1} I+w I$, then $F_{1}(x)=0, x_{1}=0$ and $x_{2}=1$ are two stable points. At this time, $F_{1}^{\prime}(0)<0$, $F_{1}^{\prime}(1)>0$, and $x_{1}=0$ is the evolutionary stable strategy of the government, indicating that when the probability of banks implementing green credit is lower than $y\left(-\beta_{1} C_{2}-M-S_{1}\right)+V_{1}-C_{1}-V_{2}+$ $S_{1}+M+w I / \beta_{1} I+w I$, the government changes from the "regulation" strategy to the "no regulation" strategy, and the "no regulation" strategy to the evolutionary stable strategy.

(3) If $z>z_{0}=y\left(-\beta_{1} C_{2}-M-S_{1}\right)+V_{1}-C_{1}-V_{2}+$ $S_{1}+M+w I / \beta_{1} I+w I$, then $F_{1}(x)=0, x_{1}=0$, and $x_{2}=1$ are two stable points. At this time, $F_{1}^{\prime}(0)>0$, $F_{1}^{\prime}(1)<0$, and $x_{2}=1$ is the evolutionary stable strategy of the government, indicating that when banks implement green credit with a probability higher than $y\left(-\beta_{1} C_{2}-M-S_{1}\right)+V_{1}-C_{1}-$ $V_{2}+S_{1}+M+w I / \beta_{1} I+w I$, the government changes from the "no regulation" strategy to the "regulation" strategy and the "regulation" strategy to the evolutionary stable strategy.

The dynamic trend chart of the government is shown in Figure 2. Let us call the three-dimensional space $Q=\{A(x, y, z) \mid 0 \leq x \leq 1,0 \leq y \leq 1,0 \leq z \leq 1\}$, and let us call $z_{0}=y\left(-\beta_{1} C_{2}-M-S_{1}\right)+V_{1}-C_{1}-V_{2}+S_{1}+M+w I / \beta_{1}$ $I+w I$ a surface $\Omega_{1}$. The space $Q$ is divided by the surface $\Omega_{1}$ into two parts, $\Omega_{11}$ and $\Omega_{12}$. When $\Omega_{11}$ is the initial state of the game, the government's final strategy after evolution is regulation. If the initial state is within $\Omega_{12}$, the ultimate policy of the government is no regulation.

3.3.2. ESCOs' Strategy Selection Analysis. Table 1 shows that ESCOs' expected perceived value $U_{C 1}$ when choosing the "undertaking retrofit" strategy and $U_{C 2}$ when choosing the "not undertaking retrofit" strategy are, respectively,

$$
\begin{aligned}
& U_{C 1}=x z\left(V_{3}+\beta_{1} C_{2}-C_{2}\right)+x(1-z)\left(V_{3}-C_{2}+\beta_{1} C_{2}\right)+z(1-x)\left(V_{3}-C_{2}\right)+(1-x)(1-z)\left(V_{3}-C_{2}\right) \\
& U_{C 2}=x z\left(V_{4}-C_{3}-M-S_{2}\right)+x(1-z)\left(V_{4}-C_{3}-M\right)+z(1-x)\left(V_{4}-C_{3}-S_{2}\right)+(1-x)(1-z)\left(V_{4}-C_{3}\right) .
\end{aligned}
$$

The ESCOs' average expected perceived value $U_{C}$ is

$$
\begin{aligned}
U_{C}= & y U_{C 1}+(1-y) U_{C 2} \\
= & y\left[x z\left(V_{3}+\beta_{1} C_{2}-C_{2}\right)+x(1-z)\left(V_{3}-C_{2}+\beta_{1} C_{2}\right)+z(1-x)\left(V_{3}-C_{2}\right)+(1-x)(1-z)\left(V_{3}-C_{2}\right)\right] \\
& +(1-y)\left[x z\left(V_{4}-C_{3}-M-S_{2}\right)+x(1-z)\left(V_{4}-C_{3}-M\right)+z(1-x)\left(V_{4}-C_{3}-S_{2}\right)+(1-x)(1-z)\left(V_{4}-C_{3}\right)\right] .
\end{aligned}
$$

The ESCOs' replication dynamic equation is as follows:

$$
F_{2}(y)=\frac{\mathrm{d} y}{\mathrm{~d} t}=y\left(U_{C 1}-U_{C}\right)=y(1-y)\left[C_{3}-V_{4}+V_{3}-C_{2}+x\left(\beta_{1} C_{2}+M\right)+z S_{2}\right]
$$

The derivative with respect to $F_{2}(y)$ is

$$
F_{2}^{\prime}(y)=\frac{\mathrm{d} F(y)}{\mathrm{d} y}=(1-2 y)\left[C_{3}-V_{4}+V_{3}-C_{2}+x\left(\beta_{1} C_{2}+M\right)+z S_{2}\right] .
$$




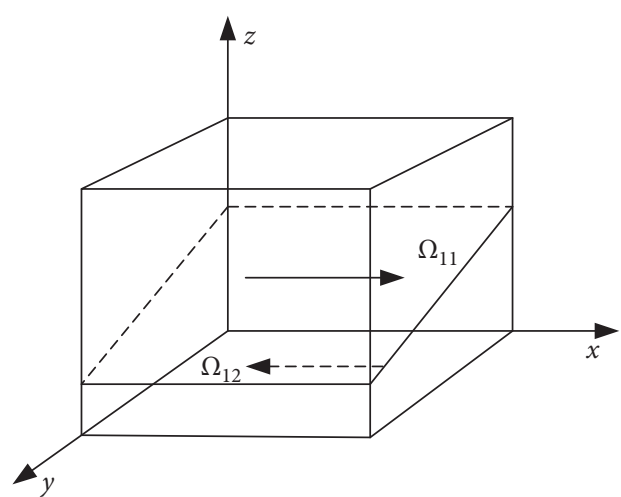

FIGURE 2: Dynamic evolution of government decision making.

Let $F_{2}(y)=0$ be the stabilization strategy point of ESCOs as $y_{1}=0, \quad y_{2}=1, \quad$ and $\quad z_{0}=V_{4}-V_{3}+$ $C_{2}-C_{3}-x\left(\beta_{1} C_{2}+M\right) / S_{2}$ which can be divided into three cases:

(1) If $z=z_{0}$, then $F_{2}(y) \equiv 0$. At this point, regardless of the value of $y$, it is a stable state.

(2) If $z<z_{0}=V_{4}-V_{3}+C_{2}-C_{3}-x\left(\beta_{1} C_{2}+M\right) / S_{2}$, then $F_{2}(y)=0, y_{1}=0$, and $y_{2}=1$ are two stable points. At this time, $F_{2}^{\prime}(0)<0, F_{2}^{\prime}(1)>0$, and $y_{1}=0$ is the evolutionary stable strategy of ESCOs, indicating that when the probability of the banks implementing green credit is lower than $V_{4}-V_{3}+C_{2}-C_{3}-x\left(\beta_{1} C_{2}+M\right) / S_{2}$, ESCOs are transformed from the "undertaking retrofit" strategy to the "not undertaking retrofit" strategy and the "not undertaking retrofit" strategy to the evolutionary stable strategy.

(3) If $z>z_{0}=V_{4}-V_{3}+C_{2}-C_{3}-x\left(\beta_{1} C_{2}+M\right) / S_{2}$, then $F_{2}(y)=0, y_{1}=0$, and $y_{2}=1$ are two stable points. At this point, $F_{2}^{\prime}(0)>0, F_{2}^{\prime}(1)<0$, and $y_{2}=1$ is the evolutionary stable strategy of ESCOs, indicating that when banks implemented green credit with a probability higher than $V_{4}-V_{3}+$ $C_{2}-C_{3}-x\left(\beta_{1} C_{2}+M\right) / S_{2}$, ESCOs' strategy changed from "not undertaking retrofit" strategy to the "undertaking retrofit" strategy and the "undertaking retrofit" strategy to the evolutionary stable strategy.

ESCOs' dynamic trend diagram is shown in Figure 3. Let us call the three dimensions $Q=\{A(x, y, z) \mid 0 \leq$ $x \leq 1,0 \leq y \leq 1,0 \leq z \leq 1\}$, and let us call $z_{0}=V_{4}-V_{3}+C_{2}-$ $C_{3}-x\left(\beta_{1} C_{2}+M\right) / S_{2}$ a surface $\Omega_{2}$. The space $Q$ is divided by the surface $\Omega_{2}$ into two parts, $\Omega_{21}$ and $\Omega_{22}$. When $\Omega_{21}$ is the initial state of the game, then ESCOs' final strategy after evolution is to undertake retrofitting. If the initial state is in $\Omega_{22}$, the ESCOs' final strategy is not undertaking retrofitting.

3.3.3. Analysis of Banks' Strategy Selection. As Table 1 shows, the expected future value $U_{B 1}$ of banks when "implementing" green credit and $U_{B 2}$ of banks when "not implementing" green credit are, respectively,

$$
\begin{aligned}
& U_{B 1}=x y\left(V_{5}-C_{4}+\beta_{2} I\right)+x(1-y)\left(V_{5}-C_{4}+\beta_{2} I\right)+y(1-x)\left(V_{5}-C_{4}\right)+(1-x)(1-y)\left(V_{5}-C_{4}\right), \\
& U_{B 2}=x y\left(V_{6}-C_{5}-w I-S_{3}\right)+x(1-y)\left(V_{6}-C_{5}-w I\right)+y(1-x)\left(V_{6}-C_{5}-S_{3}\right)+(1-x)(1-y)\left(V_{6}-C_{5}\right) .
\end{aligned}
$$

The average expected outlook value of banks is $U_{B}$ :

$$
\begin{aligned}
U_{B}= & z U_{B 1}+(1-z) U_{B 2} \\
= & z\left[x y\left(V_{5}-C_{4}+\beta_{2} I\right)+x(1-y)\left(V_{5}-C_{4}+\beta_{2} I\right)+y(1-x)\left(V_{5}-C_{4}\right)+(1-x)(1-y)\left(V_{5}-C_{4}\right)\right] \\
& +(1-z)\left[x y\left(V_{6}-C_{5}-w I-S_{3}\right)+x(1-y)\left(V_{6}-C_{5}-w I\right)+y(1-x)\left(V_{6}-C_{5}-S_{3}\right)+(1-x)(1-y)\left(V_{6}-C_{5}\right)\right] .
\end{aligned}
$$

The replication dynamic equation of banks is as follows:

$$
F_{3}(z)=\frac{\mathrm{d} z}{\mathrm{~d} t}=z\left(U_{B 1}-U_{B}\right)=z(1-z)\left[x\left(w+\beta_{2}\right) I+y S_{3}+V_{5}-C_{4}-V_{6}+C_{5}\right] .
$$

The derivative with respect to $F_{3}(z)$ is 


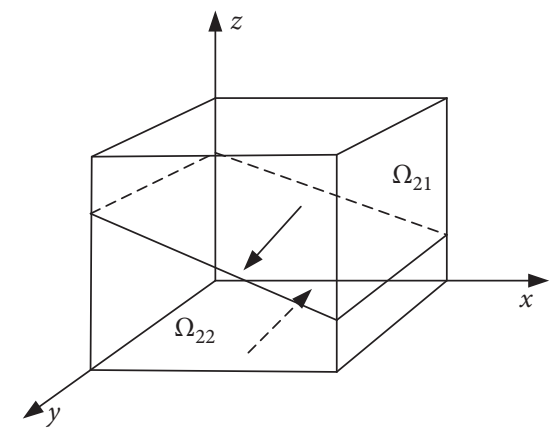

FIgURE 3: Dynamic evolution of the ESCOs' decision making.

$$
F_{3}^{\prime}(z)=\frac{\mathrm{d} F(z)}{\mathrm{d} z}=(1-2 z)\left[x\left(w+\beta_{2}\right) I+y S_{3}+V_{5}-C_{4}-V_{6}+C_{5}\right] .
$$

Let $F_{3}(z)=0$. Then, the stable strategy point of the banks is $z_{1}=0, \quad z_{2}=1$, and $y_{0}=V_{6}-C_{5}-V_{5}+C_{4}-x\left(w+\beta_{2}\right) I / S_{3}$; and then it can be divided into the following three situations:

(1) If $y=y_{0}=V_{6}-C_{5}-V_{5}+C_{4}-x\left(w+\beta_{2}\right) I / S_{3}$, then $F_{3}(z) \equiv 0$. At this point, regardless of the value of $z$, it is a stable state. This indicates that when the probability of ESCOs undertaking retrofitting is $V_{6}-C_{5}-V_{5}+C_{4}-x\left(w+\beta_{2}\right) I / S_{3}$, banks will obtain equal benefits from the "implementing green credit" or "not implementing green credit" strategy.

(2) If $y<y_{0}=V_{6}-C_{5}-V_{5}+C_{4}-x\left(w+\beta_{2}\right) I / S_{3}$, then $F_{3}(z)=0, z_{1}=0$, and $z_{2}=1$ are two stable points. At this point, $F_{3}^{\prime}(0)<0, F_{3}^{\prime}(1)>0$, and $z_{1}=0$ is the evolutionary stable strategy of the banks, indicating that when the probability of ESCOs undertaking retrofitting is lower than $V_{6}-C_{5}-V_{5}$ $+C_{4}-x\left(w+\beta_{2}\right) I / S_{3}$, the banks change from the "implementing green credit" strategy to the "not implementing green credit" strategy and the "not implementing green credit" strategy to evolutionary stable strategy.

(3) If $y>y_{0}=V_{6}-C_{5}-V_{5}+C_{4}-x\left(w+\beta_{2}\right) I / S_{3}$, then $F_{3}(z)=0, z_{1}=0$, and $z_{2}=1$ are two stable points. At this point, $F_{3}^{\prime}(0)>0, F_{3}^{\prime}(1)<0$, and $z_{2}=1$ is the evolutionary stable strategy of the banks, indicating that when ESCOs undertake retrofitting with a probability higher than $V_{6}-C_{5}-V_{5}+$ $C_{4}-x\left(w+\beta_{2}\right) I / S_{3}$, banks change from the "not implementing green credit" strategy to the "implementing green credit" strategy and the "implementing green credit" strategy to evolutionary stable strategy.

The dynamic trend chart of banks is shown in Figure 4. Let us call the three dimensions $Q=\{A(x, y, z) \mid 0 \leq$ $x \leq 1,0 \leq y \leq 1,0 \leq z \leq 1\}$, and let us call $y_{0}=V_{6}-C_{5}-V_{5}+$ $C_{4}-x\left(w+\beta_{2}\right) I / S_{3}$ a surface $\Omega_{3}$. The space $Q$ is divided by the surface $\Omega_{3}$ into two parts, called $\Omega_{31}$ and $\Omega_{32}$. When $\Omega_{31}$ is the initial state of the game, the final strategy of the banks after evolution is to implement green credit. If the initial state is in $\Omega_{32}$, the banks' final strategy is not implementing green credit.

3.3.4. Stability Analysis of Equilibrium Points. By solving the simultaneous replication dynamic equation of the government, ESCOs, and banks, and letting $F_{1}(x)=F_{2}(y)=F_{3}(z)=0$, the stable point of the threeparty game system can be obtained. If the evolutionary game equilibrium $X$ is asymptotically stable, then $X$ must be a strict Nash equilibrium, and the strict Nash equilibrium must be a pure strategic Nash equilibrium. Based on this, this paper only needs to study the stability of eight points including $E_{1}(0,0,0), E_{2}(1,0,0), E_{3}(0,1,0), E_{4}(0,0,1), E_{5}(1,1,0)$, $E_{6}(1,0,1), E_{7}(0,1,1)$, and $E_{8}(1,1,1)$ in the tripartite game system of the government, ESCOs, and banks. According to the replication dynamic equation, the Jacobian matrix is listed. The Jacobian matrix of the game system is as follows:

$$
J=\left(\begin{array}{ccc}
(1-2 x)\left[y\left(-\beta_{1} C_{2}-M-S_{1}\right)+z\left(-\beta_{2} I-w I\right)+V_{1}-C_{1}-V_{2}+S_{1}+M+w I\right] & -\left(x-x^{2}\right)\left(-\beta_{1} C_{2}-M-S_{1}\right) & -\left(x-x^{2}\right)\left[-\beta_{1} I-w I\right] \\
\left(y-y^{2}\right)\left(\beta_{1} C_{2}+M\right) & (1-2 y)\left[C_{3}-V_{4}+V_{3}-C_{2}+x\left(\beta_{1} C_{2}+M\right)+z S_{2}\right] & -\left(y-y^{2}\right) S_{2} \\
\left(z-z^{2}\right)\left(w+\beta_{2}\right) I & \left(z-z^{2}\right) S_{3} & (1-2 z)\left[x\left(w+\beta_{2}\right) I+y S_{3}+V_{5}-C_{4}-V_{6}+C_{5}\right]
\end{array}\right) .
$$

According to the above Jacobian matrix, the above 8 equilibrium points are substituted into the Jacobian matrix to obtain the eigenvalues of the Jacobian matrix corresponding to each equilibrium point. The results are shown in Table 3. 


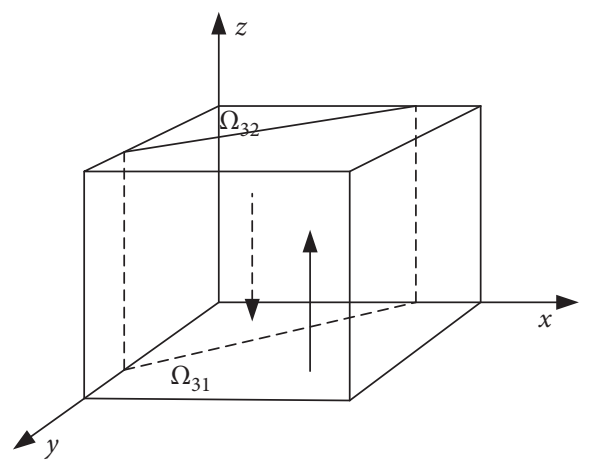

FIGURE 4: Dynamic evolution of banks' decisions making.

According to the Lyapunov indirect method, when the eigenvalues of the equilibrium point are all negative, the equilibrium point is an evolutionarily stable strategy; otherwise, it is an unstable point. Table 3 shows that the stability of the eight points cannot be determined, and their stability needs to be judged by combining the specific conditions and the values of the parameters. According to prospect theory, the decision of each subject is determined by its psychological perception of benefits. When the government chooses to regulate, the perceived value gained by the government should be greater than the perceived costs, $V_{1}>C_{1}$. Similarly, regardless of the strategy the banks and ESCOs choose, the perceived benefits obtained should be greater than the costs. As a result, when $V_{1}-C_{1}+M+w I<V_{2}-S_{1}, \quad V_{3}-C_{2}<V_{4}-C_{3}, \quad$ and $V_{5}-C_{4}<V_{6}-C_{5}, E_{1}(0,0,0)$ is a stable point. At this time, the strategy choice is that the government does not regulate, ESCOs do not undertake retrofitting, and the banks do not implement green credit. When $V_{1}-C_{1}-\beta_{1} C_{2}+w I>V_{2}$, $V_{3}-C_{2}+\beta_{1} C_{2}>V_{4}-C_{3}-M$, and $V_{5}-C_{4}+\beta_{2} I<V_{6}$ $-C_{5}-w I-S_{3}, E_{5}(1,1,0)$ is a stable point, that is, the government regulates, ESCOs undertake retrofitting, and banks do not implement green credit. When $V_{1}-C_{1}-\beta_{1} I-\beta_{2} C_{4}>V_{2}, \quad \beta_{1} C_{2}+V_{3}-C_{2}>V_{4}-$ $C_{3}-S_{2}-M$, and $V_{5}-C_{4}+\beta_{2} I>\quad V_{6}-C_{5}-S_{3}-w I$, $E_{8}(1,1,1)$ is a stable point. At this time, the government implements regulation, ESCOs undertake retrofitting, and banks implement green credit. Therefore, the initial values of the different parameters have different effects on the game's evolutionary process.

\subsection{Stability Analysis of the Government-ESCOs-Owners Equilibrium}

3.4.1. Analysis of Government's Strategy Selection. According to Table 2, it is assumed that the expected perceived value $U_{G 1}$ when the government chooses the "regulation" strategy and the expected perceived value $U_{G 2}$ when the government chooses the "no regulation" strategy are, respectively,

$$
\begin{aligned}
& U_{G 1}=y r\left(V_{1}-\beta_{1} C_{2}-B-C_{1}\right)+r(1-y)\left(V_{1}-C_{1}+M\right)+(1-r) y\left(V_{1}-C_{1}\right)+(1-r)(1-y)\left(V_{1}-C_{1}\right), \\
& U_{G 2}=y r V_{2}+r(1-y)\left(V_{2}-S_{1}\right)+y(1-r) V_{2}+(1-r)(1-y)\left(V_{2}-S_{1}\right) .
\end{aligned}
$$

The average expected perceived value of the government $U_{G}$ is

$$
\begin{aligned}
U_{G}= & x U_{G 1}+(1-x) U_{G 2} \\
= & x\left[y r\left(V_{1}-\beta_{1} C_{2}-B-C_{1}\right)+r(1-y)\left(V_{1}-C_{1}+M\right)+(1-r) y\left(V_{1}-C_{1}\right)+(1-r)(1-y)\left(V_{1}-C_{1}\right)\right] \\
& +(1-x)\left[y r V_{2}+r(1-y)\left(V_{2}-S_{1}\right)+y(1-r) V_{2}+(1-r)(1-y)\left(V_{2}-S_{1}\right)\right] .
\end{aligned}
$$
follows:

The government's replication dynamic equation is as

$$
F_{4}(X)=\frac{\mathrm{d} x}{\mathrm{~d} t}=x\left(U_{G 1}-U_{G}\right)=x(1-x)\left[y r\left(-\beta_{1} C_{2}-M-B\right)+r M-y S_{1}+V_{1}-C_{1}-V_{2}+S_{1}\right]
$$

The derivative with respect to $F_{4}(x)$ is 


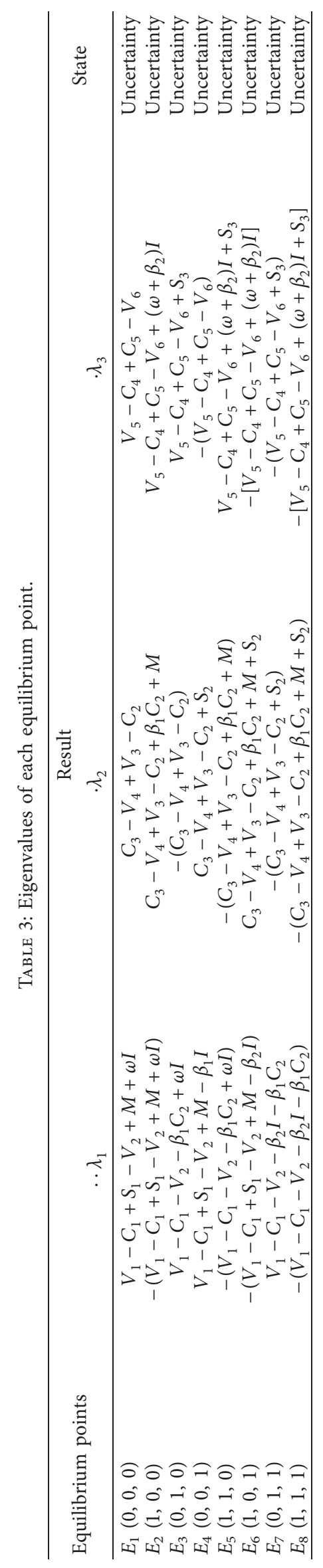




$$
F_{4}^{\prime}(x)=\frac{\mathrm{d} F(x)}{\mathrm{d} x}=(1-2 x)\left[y r\left(-\beta_{1} C_{2}-M-B\right)+r M-y S_{1}+V_{1}-C_{1}-V_{2}+S_{1}\right] .
$$

Let $F_{4}(X)=0$. Then, the stable strategy points $x_{1}=0$, $x_{2}=1$, and $y_{0}=V_{1}-C_{1}+r M+S_{1}-V_{2} / r\left(\beta_{1} C_{2}+M+B\right)+$ $S_{1}$ of the government can be divided into three situations for discussion:

(1) If $y=y_{0}=V_{1}-C_{1}+r M+\quad S_{1}-V_{2} / r\left(\beta_{1} C_{2}+\right.$ $M+B)+S_{1}$, then $F_{4}(X) \equiv 0$. At this point, regardless of the value of $x$, this is a stable state. This shows that when the ESCOs' probability of undertaking retrofitting is $V_{1}-C_{1}+r M+$ $S_{1}-V_{2} / r\left(\beta_{1} C_{2}+M+B\right)+S_{1}$, the government will obtain equal benefits by choosing the "regulation" or "no regulation" strategy.

(2) If $y<y_{0}=V_{1}-C_{1}+r M+S_{1}-V_{2} / \quad r\left(\beta_{1} C_{2}+\right.$ $M+B)+S_{1}$, then $F_{4}(X)=0, x_{1}=0$, and $x_{2}=1$ are two stable points. At this point, $F_{4}^{\prime}(0)<0, F_{4}^{\prime}(1)>0$, and $\mathrm{x}_{1}=0$ are the evolutionary stable strategy of the government, indicating that when the probability of ESCOs undertaking retrofitting is lower than $V_{1}-C_{1}+r M+S_{1}-V_{2} / r\left(\beta_{1} C_{2}+M+B\right)+S_{1}$, the government changes from the "regulation" strategy to the "no regulation" strategy and the "no regulation" strategy to the evolutionary stable strategy.

(3) If $y>y_{0}=V_{1}-C_{1}+r M+S_{1}-V_{2} / r \quad\left(\beta_{1} C_{2}+\right.$ $M+B)+S_{1}$, then $F_{4}(X)=0, x_{1}=0$, and $x_{2}=1$ are two stable points. At this point, $F_{4}^{\prime}(0)>0, F_{4}^{\prime}(1)<0$, and $x_{2}=1$ are the evolutionary stable strategy of the government, indicating that when ESCOs undertake retrofitting with a probability higher than $V_{1}-C_{1}+r M+S_{1}-V_{2} / r\left(\beta_{1} C_{2}+M+B\right)+S_{1}$, the government changes from the "no regulation" strategy to the "regulation" strategy and the "regulation" strategy to the evolutionary stable strategy.

The trend chart of the government's evolutionary game is shown in Figure 5. Let us call the three dimensions $N=\{B(x, y, r) \mid 0 \leq x \leq 1,0 \leq y \leq 1,0 \leq r \leq 1\}$, and let us call $y_{0}=V_{1}-C_{1}+r M+S_{1}-V_{2} / r\left(\beta_{1} C_{2}+M+B\right)+S_{1}$ surface $\Phi_{1}$. The space $\mathrm{N}$ is divided by the surface $\Phi_{1}$ into two parts, called $\Phi_{11}$ and $\Phi_{12}$. When $\Phi_{11}$ is the initial state of the game, the government's final strategy after evolution is regulation. If the initial state is $\Phi_{12}$, the government's ultimate strategy is not regulation.

3.4.2. ESCOs' Strategy Selection Analysis. According to Table 2, assume that the expected perceived value $U_{C 1}$ when ESCOs choose the "undertaking retrofit" strategy and the expected perceived value $U_{C 2}$ when ESCOs choose the "not undertaking retrofit" strategy are

$$
\begin{aligned}
& \left.U_{C 1}=x r\left(V_{3}-C_{2}+\beta_{1} C_{2}\right)+x(1-r)\left(V_{3}-C_{2}-S_{2}\right)+r(1-x)\left(V_{3}-C_{2}\right)+(1-x)\right)(1-r)\left(V_{3}-C_{2}-S_{2}\right), \\
& U_{C 2}=x r\left(V_{4}-C_{3}-M-S_{2}\right)+x(1-r)\left(V_{4}-C_{3}\right)+r(1-x)\left(V_{4}-C_{3}-S_{2}\right)+(1-x)(1-r)\left(V_{4}-C_{3}\right) .
\end{aligned}
$$

ESCOs' average expected perceived value $U_{C}$ is

$$
\begin{aligned}
U_{C}= & y U_{C 1}+(1-y) U_{C 2} \\
= & y\left[x r\left(V_{3}-C_{2}+\beta_{1} C_{2}\right)+x(1-r)\left(V_{3}-C_{2}-S_{2}\right)+r(1-x)\left(V_{3}-C_{2}\right)+(1-x)(1-r)\left(V_{3}-C_{2}-S_{2}\right)\right] \\
& +(1-y)\left[x r\left(V_{4}-C_{3}-M-S_{2}\right)+r(1-x)\left(V_{4}-C_{3}-S_{2}\right)+x(1-r)\left(V_{4}-C_{3}\right)+(1-x)(1-r)\left(V_{4}-C_{3}\right)\right] .
\end{aligned}
$$

ESCOs' replication dynamic equation is as follows:

$$
F_{5}(y)=\frac{\mathrm{d} y}{\mathrm{~d} t}=y\left(U_{B 1}-U_{B}\right)=y(1-y)\left[x r\left(M+\beta_{1} C_{2}\right)+2 r S_{2}+V_{3}-C_{2}-V_{4}+C_{3}-S_{2}\right]
$$

The derivative with respect to $F_{5}(y)$ is 


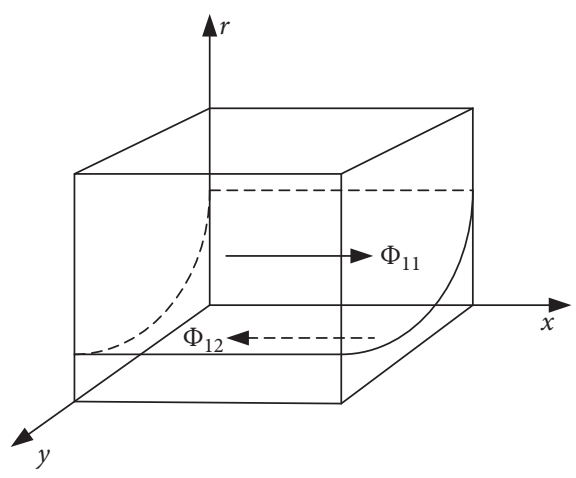

FIGURE 5: Dynamic evolution of government decision making.

$$
F_{5}^{\prime}(y)=\frac{\mathrm{d} F(y)}{\mathrm{d} y}=(1-2 y)\left[x r\left(M+\beta_{1} C_{2}\right)+2 r S_{2}+V_{3}-C_{2}-V_{4}+C_{3}-S_{2}\right]
$$

If $F_{5}(y)=0$, then the ESCOs' stable strategy point is $y_{1}=0, y_{2}=1, \quad$ and $\quad x_{0}=V_{4}+S_{2}+C_{2}-V_{3}-C_{3}-$ $2 r S_{2} / r\left(M+\beta_{1} C_{2}\right)$. Then, there are three cases as follows:

(1) If $\quad x=x_{0}=V_{4}+S_{2}+\quad C_{2}-V_{3}-C_{3}-2 r S_{2} / r$ $\left(M+\beta_{1} C_{2}\right)$, then $F_{5}(y) \equiv 0$. At this point, regardless of the value of $y$, it is a stable state. If $X \neq X_{0}$, then $y_{1}=0$ and $y_{2}=1$ are two stable points. This shows that when the probability of the government implementing regulations is $\mathrm{V}_{4}+\mathrm{S}_{2}+\mathrm{C}_{2}-$ $V_{3}-C_{3}-2 r S_{2} / r\left(M+\beta_{1} C_{2}\right)$, ESCOs choose the "undertaking retrofit" or "not undertaking retrofit" strategy to obtain equal benefits.

(2) If $\quad x<x_{0}=V_{4}+S_{2}+C_{2}-\quad V_{3}-C_{3}-2 r S_{2} / r$ $\left(M+\beta_{1} C_{2}\right)$, then $F_{5}(y)=0, y_{1}=0$, and $y_{2}=1$ are two stable points. At this time, $F_{5}^{\prime}(0)<0, F_{5}^{\prime}(1)>0$, and $y_{1}=0$ are the evolutionary stable strategy of ESCOs, indicating that when the probability of government regulation was lower than $V_{4}+S_{2}+$ $C_{2}-V_{3}-C_{3}-2 r S_{2} / r\left(M+\beta_{1} C_{2}\right)$, ESCOs changed from the "undertaking retrofit" strategy to the "not undertaking retrofit" strategy and the "not undertaking retrofit" strategy to the evolutionary stable strategy.

(3) If $x>x_{0}=V_{4}+S_{2}+C_{2}-V_{3}-C_{3}-2 r S_{2} / r(M+$ $\left.\beta_{1} C_{2}\right)$, then $F_{5}(y)=0, y_{1}=0$, and $y_{2}=1$ are two stable points. At this time, $F_{5}^{\prime}(0)>0, F_{5}^{\prime}(1)<0$, and $y_{2}=1$ are the evolutionary stable strategy of ESCOs, indicating that when the government regulates with a probability higher than $V_{4}+S_{2}+C_{2}-$ $V_{3}-C_{3}-2 r S_{2} / r\left(M+\beta_{1} C_{2}\right)$, ESCOs' strategy is transformed into the undertake retrofitting strategy, and the undertake retrofitting strategy becomes the evolutionary stable strategy.

ESCOs' dynamic trend diagram is shown in Figure 6. Let us call the three dimensions $N=\{B(x, y, r) \mid 0 \leq x$ $\leq 1,0 \leq y \leq 1,0 \leq r \leq 1\}$, and let us call $x_{0}=V_{4}+S_{2}+C_{2}-$ $V_{3}-C_{3}-2 r S_{2} / r\left(M+\beta_{1} C_{2}\right)$ the surface $\Phi_{2}$. The space $\mathrm{N}$ is divided by the surface $\Phi_{2}$ into two parts, $\Phi_{21}$ and $\Phi_{22}$. When $\Phi_{21}$ is the initial state of the game, then ESCO's final strategy after evolution is to undertake retrofitting. If the initial state is in $\Phi_{22}$, ESCOs' final strategy is not to undertake retrofitting.

3.4.3. Existing Building Owners' Decision Analysis. According to Table 1, it is assumed that the expected perceived value $U_{O 1}$ when the existing building owners choose the "conducting retrofitting" strategy and the expected perceived value $U_{\mathrm{O} 2}$ when the existing building owners choose the "not conducting retrofitting" strategy are, respectively,

$$
\begin{aligned}
& U_{\mathrm{O} 1}=x y\left(V_{7}+B-C_{6}\right)+x(1-y)\left(V_{7}-C_{6}-S_{4}\right)+y(1-x)\left(V_{7}-C_{6}\right)+(1-x)(1-y)\left(V_{7}-C_{6}-S_{4}\right), \\
& U_{O 2}=x y * 0+x(1-y) * 0+y(1-x) * 0+(1-x)(1-y) * 0 .
\end{aligned}
$$

The average expected perceived value of existing building owners $U_{\mathrm{O}}$ is 


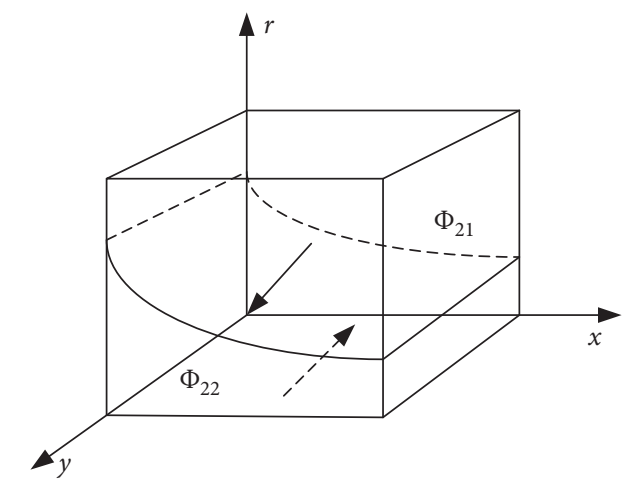

FIgURE 6: Dynamic evolution of ESCOs' decisions making.

$$
\begin{aligned}
U_{O}= & r U_{O 1}+(1-r) U_{02} \\
= & r\left[x y\left(V_{7}+B-C_{6}\right)+x(1-y)\left(V_{7}-C_{6}-S_{4}\right)+y(1-x)\left(V_{7}-C_{6}\right)+(1-x)(1-y)\left(V_{7}-C_{6}-S_{4}\right)\right] \\
& +(1-r)[x y * 0+x(1-y) * 0+y(1-x) * 0+(1-x)(1-y) * 0] .
\end{aligned}
$$

The replication dynamic equation of existing building owners is as follows:

$$
F_{6}(r)=\frac{\mathrm{d} r}{\mathrm{~d} t}=r\left(U_{O 1}-U_{O}\right)=r(1-r)\left[x y B+y S_{4}+V_{7}-C_{6}-S_{4}\right]
$$

The derivative with respect to $F_{6}(r)$ is

$F_{6}^{\prime}(r)=\frac{\mathrm{d} F(r)}{\mathrm{d} r}=(1-2 r)\left[x y B+y S_{4}+V_{7}-C_{6}-S_{4}\right]$.

Let $F_{6}(r)=0$. Then, the stable strategy points of existing building owners are $r_{1}=0, r_{2}=1$, and $x_{0}=C_{6}+S_{4}-$ $y S_{4}-V_{7} / y B$, which can be divided into three situations:

(1) If $x=x_{0}=C_{6}+S_{4}-y S_{4}-V_{7} / y B$, then $F_{6}(r) \equiv 0$. At this point, regardless of the value of $r$, it is a stable state.

(2) If $x<x_{0}=C_{6}+S_{4}-y S_{4}-V_{7} / y B$, then $F_{6}(r)=0$, $r_{1}=0$, and $r_{2}=1$ are two stable points. At this point, $F_{6}^{\prime}(0)<0 F_{6}^{\prime}(1)>0$, and $r_{1}=0$ are the evolutionary stable strategy of the owners, indicating that when the probability of government regulation is lower than $C_{6}+S_{4}-y S_{4}-V_{7} / y B$, the owners change from the "conducting retrofitting" strategy to the "not conducting retrofitting" strategy and the "not conducting retrofitting" strategy to the evolutionary stable strategy.

(3) If $x>x_{0}=C_{6}+S_{4}-y S_{4}-V_{7} / y B$, then $F_{6}(r)=0$, $r_{1}=0$, and $r_{2}=1$ are two stable points. At this point,
$F_{6}^{\prime}(0)>0, \quad F_{6}^{\prime}(1)<0$, and $r_{2}=1$ are the owners' evolutionary stable strategy, indicating that when the probability of government regulation is higher than $C_{6}+S_{4}-y S_{4}-V_{7} / y B$, the "not conducting retrofitting" strategy is transformed into the "conducting retrofitting" strategy, and the "conducting retrofitting" strategy is transformed into the evolutionary stable strategy.

The dynamic trend chart of the owners is shown in Figure 7. Let us call the three dimensions $N=\{B(x, y, r) \mid 0 \leq x \leq 1,0 \leq y \leq 1,0 \leq r \leq 1\}$, and let us call $x_{0}=C_{6}+S_{4}-y S_{4}-V_{7} / y B$ surface $\Phi_{3}$. The space $N$ is divided by the surface $\Phi_{3}$ into two parts, called $\Phi_{31}$ and $\Phi_{32}$. When $\Phi_{31}$ is the initial state of the game, the final strategy of the owners after evolution is conducting retrofitting. If the initial state is in $\Phi_{32}$, the owners' final strategy is not conducting retrofitting.

3.4.4. Analysis of the Stable Strategy of a Three-Party Evolutionary Game. Let $F_{4}(x)=F_{5}(y)=F_{6}(r)=0$. The stable point of the three-party game system is obtained, and the Jacobian matrix is given. The Jacobian matrix of the threeparty game system is as follows: 


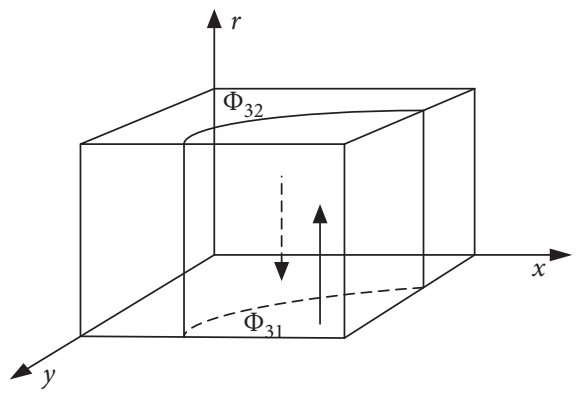

FIGURE 7: Dynamic evolution of owners' decision making.

$$
J=\left(\begin{array}{ccc}
(1-2 x)\left[y r\left(-\beta_{1} C_{2}-M-B\right)+r M-y S_{1}+V_{1}-C_{1}-V_{2}+S_{1}\right] & \left(x-x^{2}\right)\left[r\left(-\beta_{1} C_{2}-M-B\right)-S_{1}\right] & \left(x-x^{2}\right)\left[y\left(-\beta_{1} C_{2}-M-B\right)+M\right] \\
\left(y-y^{2}\right) r\left(M+\beta_{1} C_{2}\right) & (1-2 y)\left[x r\left(M+\beta_{1} C_{2}\right)+2 r S_{2}+V_{3}-C_{2}-V_{4}+C_{3}-S_{2}\right] & \left(y-y^{2}\right)\left[x\left(M+\beta_{1} C_{2}\right)+2 S_{2}\right] \\
\left(r-r^{2}\right) B & \left(r-r^{2}\right) S_{4} & (1-2 z)\left[x y B+y S_{4}+V_{7}-C_{6}-S_{4}\right]
\end{array}\right) .
$$

Based on the above Jacobian matrix, the determinant and trace of each equilibrium point are calculated, as shown in Table 4.

When the government chooses to regulate, the perceived value obtained by the government should be greater than the perceived costs, $V_{1}>C_{1}$. Similarly, the perceived value obtained by the owners when they choose to conduct green retrofitting should be greater than the retrofitting costs, $V_{7}>C_{6}$. This is consistent with the actual situation. Therefore, points $E_{3}(0,1,0)$ and $E_{5}(1,1,0)$ are unstable points, and the stability of the remaining six points is uncertain, which needs to be judged in combination with specific conditions. When $V_{1}-C_{1}-\beta_{1} C_{2}-B<V_{2}$ and $V_{3}-C_{2}>V_{4}-C_{3}-S_{2}$, $E_{7}(0,1,1)$ is the stable point; that is, the government does not regulate, ESCOs undertake retrofitting, and the owners conduct green retrofitting. When $V_{1}-C_{1}-\beta_{1} C_{2}-$ $B>V_{2}$ and $\beta_{1} C_{2}+V_{3}-C_{2}>V_{4}-C_{3}-S_{3}-M, E_{8}(1,1,1)$ is the stable point. At this time, the government implements regulations, ESCOs undertake retrofitting, and the owners conduct retrofitting.

\section{Numerical Simulation and Results}

In order to investigate the influence and significance of various factors on the strategy selection of the government, ESCOs, banks, and existing building owners, according to the known conditions in the hypothesis, MATLAB is used to simulate the dynamic evolutionary process of each participant's behavior [35-38]. The values of the relevant parameters are as follows: $V_{1}=30, V_{2}=18, V_{3}=25, V_{4}=23$, $V_{5}=30, V_{6}=26, V_{7}=15, C_{1}=4, C_{2}=10, C_{3}=7, C_{4}=12$, $C_{5}=7, C_{6}=5, S_{1}=5, S_{2}=4, S_{3}=5, S_{4}=3, B=2, \beta_{1}=0.1$, $\beta_{2}=0.1, \omega=0.1, I=50$, and $M=2$. In addition, different initial values are given to the government, ESCOs, banks, and owners to study the influences of major factor changes on the evolutionary stable strategy.
4.1. Baseline Evolution Path Analysis. As Figures 8 and 9 show, based on the above assignment, the initial proportion is constantly changed. Finally, the government will choose to implement regulations, ESCOs will undertake retrofitting, banks will implement green credit, and owners will conduct retrofitting.

On the basis of the above analysis, the influence of different parameter values on the strategy selection of each subject is explored by changing the corresponding parameters.

4.2. Effects of $\beta_{1}$ and $\beta_{2}$. By changing the values of $\beta_{1}$ and $\beta_{2}$, the influences on the government's, ESCOs', and banks' strategy choices are explored. As Figure 10 shows, as the government subsidy coefficient increases, the government's strategy will change from implementing regulations to not implementing regulations, ESCOs choose to undertake retrofitting, and banks choose to implement green credit at a faster speed. This indicates that the government's regulatory costs increase with the strengthening of subsidies. When the subsidy exceeds a certain amount, the government will not regulate. However, the more subsidies that ESCOs and banks receive can promote ESCOs to undertake retrofitting and banks to implement green credit.

4.3. $C_{2}$ and $S_{2}$ Influence on ESCOs' Strategy Selection. By changing the values of $C_{2}$ and $S_{2}$, the influence of $S_{2}$ and $S_{2}$ on ESCOs' strategy selection was explored. As Figures 11 and 12 show, as $C_{2}$ increases, the ESCOs' strategy will change from undertaking retrofitting to not undertaking retrofitting. ESCOs need to pay corresponding costs to undertake green retrofitting and improve their own technology. When the costs of ESCOs to undertake retrofitting exceed a certain amount, the benefits of ESCOs decrease, and ESCOs tend to choose not to undertake retrofitting, while, as $S_{2}$ increases, ESCOs choose to undertake retrofitting at a faster speed. 
TABLE 4: Eigenvalues of each equilibrium point.

\begin{tabular}{lcccc}
\hline Equilibrium points & $\cdots \lambda_{1}$ & Result & State \\
\hline$E_{1}(0,0,0)$ & $V_{1}-C_{1}-V_{2}+S_{1}$ & $\lambda_{2}$ & $\lambda_{3}$ \\
$E_{2}(1,0,0)$ & $-\left(V_{1}-C_{1}-V_{2}+S_{1}\right)$ & $V_{3}-C_{2}-V_{4}+C_{3}-S_{2}$ & $V_{7}-C_{6}-S_{4}$ & Uncertainty \\
$E_{3}(0,1,0)$ & $V_{1}-C_{1}-V_{2}$ & $V_{3}-C_{2}-V_{4}+C_{3}-S_{2}$ & $V_{7}-C_{6}-S_{4}$ & Uncertainty \\
$E_{4}(0,0,1)$ & $\mathrm{M}+S_{1}-V_{2}+V_{1}-C_{1}$ & $-\left(V_{3}-C_{2}-V_{4}+C_{3}-S_{2}\right)$ & $V_{7}-C_{6}$ & Instability point \\
$E_{5}(1,1,0)$ & $-\left(V_{1}-C_{1}-V_{2}\right)$ & $V_{3}-C_{2}-V_{4}+C_{3}+S_{2}$ & $-\left(V_{7}-C_{6}-S_{4}\right)$ & Uncertainty \\
$E_{6}(1,0,1)$ & $-\left(\mathrm{M}+S_{1}-V_{2}+V_{1}-C_{1}\right)$ & $V_{3}-C_{2}-V_{4}+C_{3}+S_{2}+M+\beta_{1} C_{2}$ & $-\left(V_{7}-C_{6}-S_{4}\right)$ & Instability point \\
$E_{7}(0,1,1)$ & $V_{1}-V_{2}-C_{1}-\beta_{1} C_{2}-B$ & $-\left(V_{3}-C_{2}-V_{4}+C_{3}+S_{2}\right)$ & $-\left(V_{7}-C_{6}\right)$ & Uncertainty \\
$E_{8}(1,1,1)$ & $-\left(V_{1}-V_{2}-C_{1}-\beta_{1} C_{2}-B\right)$ & $-\left(V_{3}-C_{2}-V_{4}+C_{3}+S_{2}+M+\beta_{1} C_{2}\right)$ & $-\left(V_{7}-C_{6}+B\right)$ & Uncertainty \\
\hline
\end{tabular}

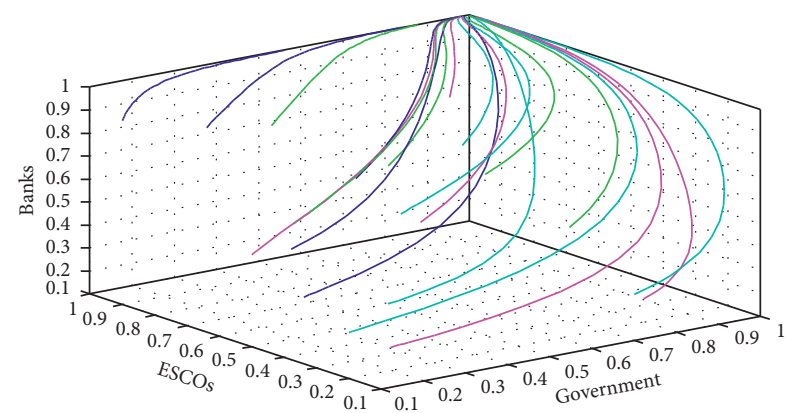

Figure 8: Government-ESCOs-banks.

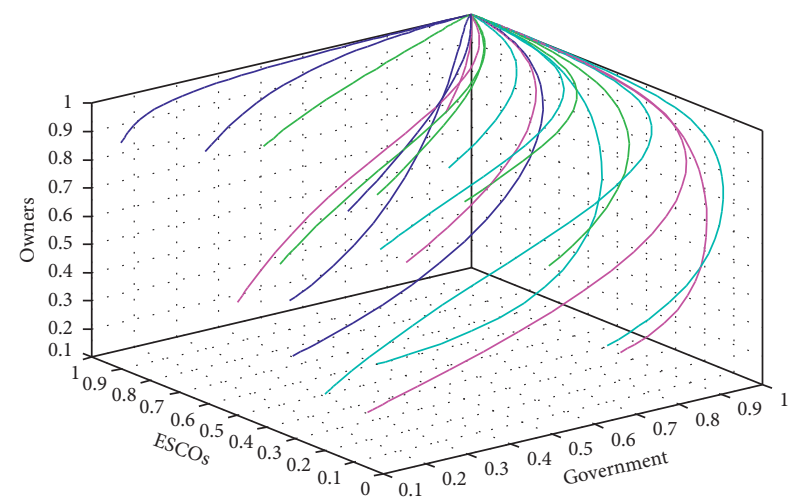

FIGURE 9: Government-ESCOs-owners.

4.4. Influence of $S_{3}$ on Banks' Strategy Selection. Explore the change in banks' strategy selection by changing the value of $S_{3}$. As Figure 13 shows, as $S_{3}$ increases, banks will be more inclined to implement green credit. The credibility of a bank is extremely important. A good reputation helps the bank gain public trust. Therefore, failure to implement green credit will have a serious negative impact on banks, and they will suffer greater losses, and the banks will be increasingly more inclined to implement green credit.

4.5. Influence of $C_{6}$ and $B$ on Owners' Choice of Strategy. By changing the values of $C_{6}$ and $B$, we explore the influence of different values on owners. Figures 14 and 15 show that as $C_{6}$ increases, the strategy of the owners will gradually change from conducting retrofitting to not conducting retrofitting, while, as $B$ increases, the speed of the owners choosing to

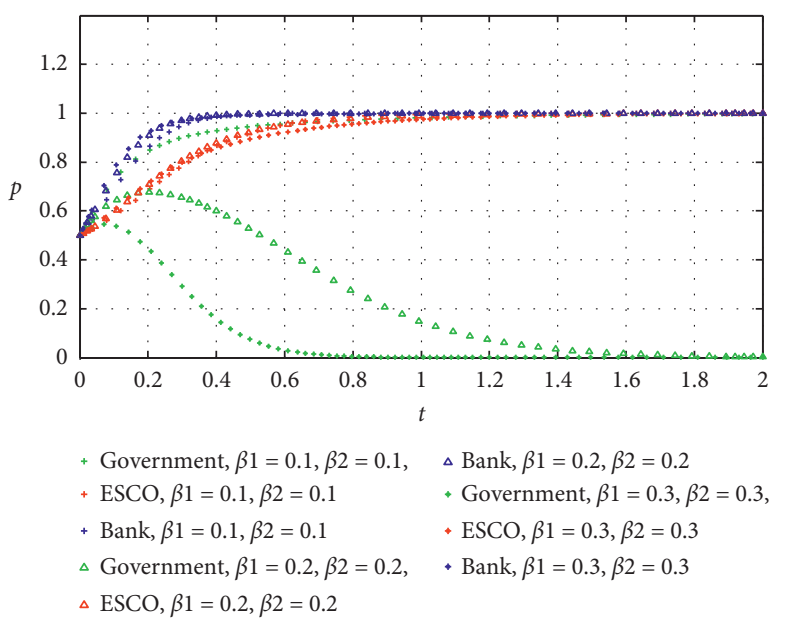

FIgURE 10: The evolutionary trajectory of the government's, ESCOs', and banks' behaviors under different $\beta_{1}$ and $\beta_{2}$.

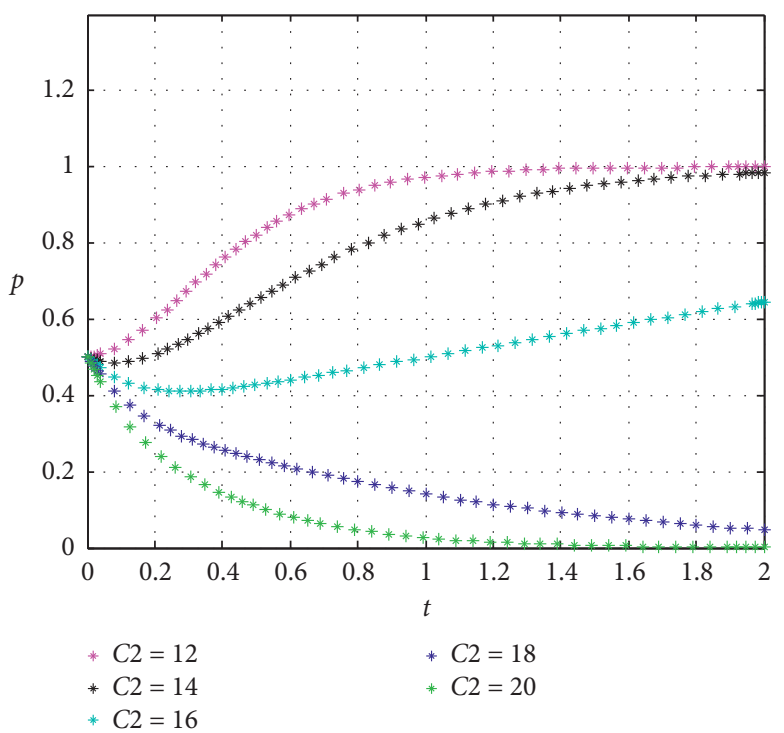

FIGURE 11: ESCOs' behavior evolution trajectory under different $\mathrm{C}_{2}$.

conduct retrofitting will accelerate. Whether owners conduct retrofitting is closely related to the income and costs of green retrofitting, and the owners' perceived benefit and 


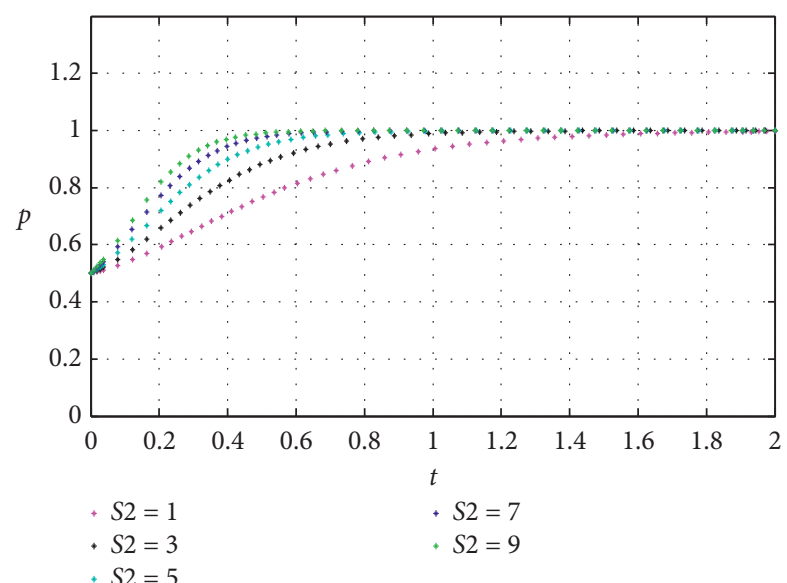

FIGURE 12: Evolutionary trajectory of ESCOs' behavior under different $S_{2}$.

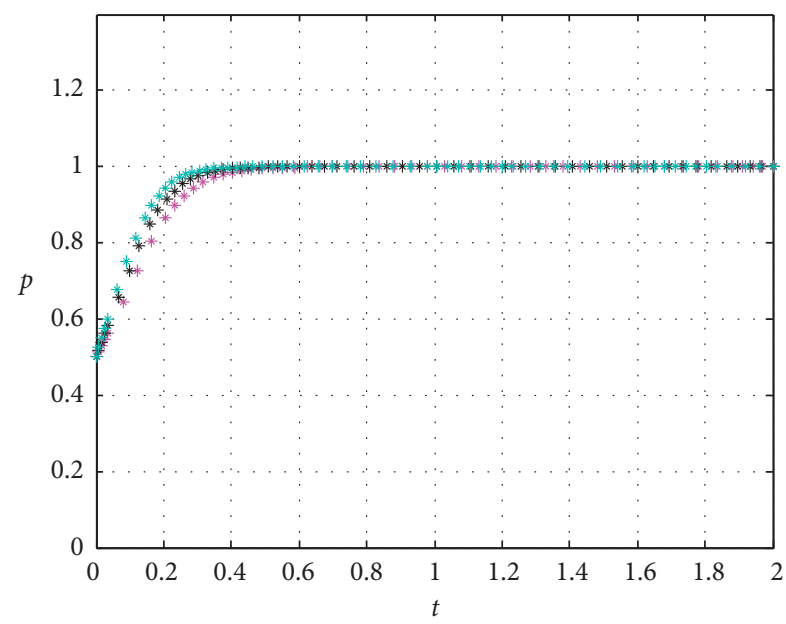

$* S 3=5$

* $S 3=9$

* $S 3=13$

FIGURE 13: Evolutionary trajectory of banks' behavior under different $S_{3}$.

willingness to retrofit will decrease as the cost increases. The subsidy given by the government will reduce the cost of retrofitting and increase their willingness to conduct retrofitting.

\section{Conclusions and Recommendations}

This paper introduces prospect theory, takes green credit as the perspective, and analyzes the evolutionary processes of the four types of participants' strategic choices by constructing a three-party interactive evolutionary game model of the government, ESCOs, banks, and existing building owners. Moreover, MATLAB is used for the simulation analysis. The results show the following:

(1) In the two game models, the strategy choices of the government, ESCOs, banks, and owners are influenced by each other; and the initial probability of

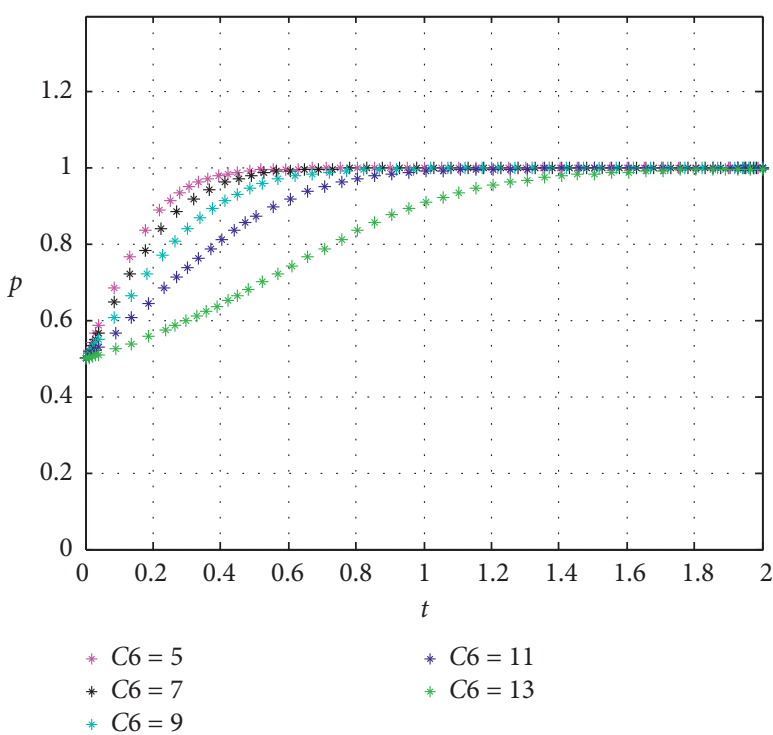

Figure 14: Evolutionary trajectory of owners' behavior under different $C_{6}$.

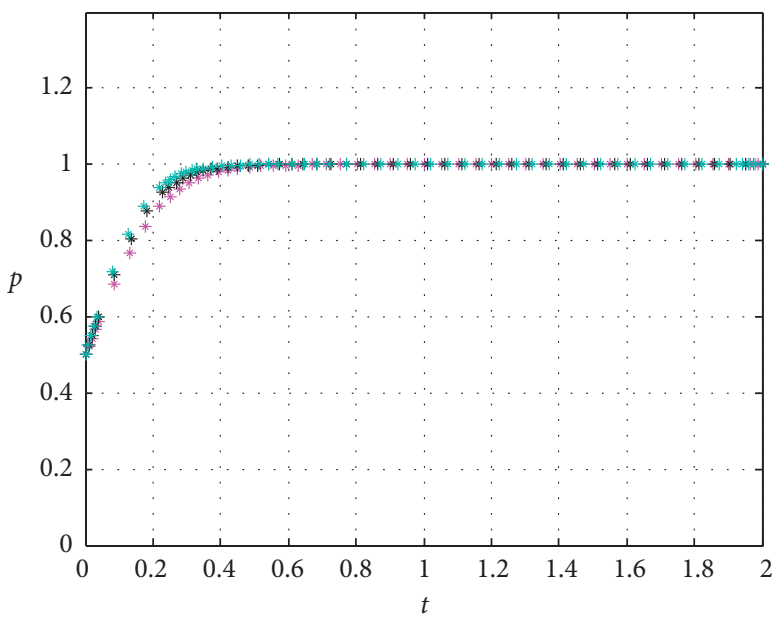

$$
\begin{aligned}
& * B=2 \\
& * B=6 \\
& * B=10
\end{aligned}
$$

FIgURE 15: Evolutionary trajectory of owners' behavior under different $B$.

each participant participating in the green retrofit will have an impact on the enthusiasm of other participants participating in green retrofitting.

(2) The strategic choice of the government is related to the perceived benefits, regulatory costs, and subsidy of the implemented regulation. The government's willingness to implement regulation is directly proportional to the government's perceived benefits. On the contrary, when the total cost of government regulation exceeds the benefit, the government will not choose regulation.

(3) For banks, loan interest is a major source of income. The implementation of green credit means that 
banks' lending objects are limited, which will have a certain impact on banks' profits. As government regulation increases, subsidies and penalties will encourage banks to implement green credit.

(4) ESCOs' strategy choice is mainly influenced by the costs and benefits of retrofitting and the intensity of government regulation. Government subsidies can compensate for the incremental costs of ESCOs to undertake retrofitting. In prospect theory, agents always overestimate low probability losses, so the punitive measures implemented will increase the perceived losses of ESCOs and enhance the willingness of ESCOs to undertake retrofitting. ESCOs are actively undertaking retrofitting and can push the government to regulate and banks to implement green credit.

(5) Owners will evaluate the additional costs and benefits of improving their energy efficiency [34] and make strategic choices based on the costs and benefits. The government should subsidize the owners who conduct retrofitting so as to motivate the owners to conduct retrofitting, improve the demand for green retrofitting, drive the supply side from the demand side, and promote the development of the green retrofitting market.

Based on the above research conclusions, the following suggestions are proposed:

(1) The government should build a good policy environment and formulate corresponding policies, laws, and regulations. Increasing publicity efforts, changing the thinking modes of market participants, and improving the environmental protection awareness of all participants play extremely important roles in building energy conservation. The government should implement tax support policies to improve the financial environment and promote the rapid development of green credit. Corresponding financial subsidies should be given to commercial banks implementing the green credit policy, and discount interest loans should be given to green development projects [17], which will urge banks, ESCOs, and owners to actively participate in the existing building green retrofitting. Furthermore, the earlier all stakeholders participate in the design process, the more successful they will be [39]. The government can establish a multiagent information linkage mechanism to achieve information transparency, increase information disclosure, and implement ESCO ratings so as to alleviate the information asymmetry among various subjects. Effective information helps reduce owners' risk perception, thus stimulating their initiative for cooperation [40].

(2) As important financial institutions, banks play an important role in green retrofitting. Therefore, banks should improve their sense of responsibility, respond to the call of the government, actively implement green credit, establish a responsibility system or functional department focusing on environmental risk inspection and identification, formulate corresponding assessment and incentive mechanisms [40], and establish a sound corporate environmental protection rating system. We can increase loans to environmental enterprises and actively solve their financing problems.

(3) ESCOs should actively fulfill their social responsibility, take the initiative to undertake green retrofitting, improve technological innovation ability, and regularly conduct technological exchanges or establish enterprise alliances with technologically advanced enterprises. In addition, enterprises can improve their service efficiency by developing new technologies, reduce project management costs with a high-quality service level, and improve energy efficiency. Furthermore, ESCOs should improve their own financial management system and enhance their own strength, which is more conducive to obtaining financing.

(4) Whether owners conduct retrofitting is the key to the large-scale development of the existing building green retrofitting market. Owners should change their utility maximization concept, pay active attention to environmental issues, timely grasp the policies and relevant knowledge of green retrofitting, and further improve their initiative to participate and cooperate. By enhancing the owners' awareness of energy conservation, and changing the unique concept of interests, the owners' recognition of the existing building green retrofitting can be improved. This will make it easier to transform potential demand into explicit demand, providing space for market development.

\section{Data Availability}

In order to investigate the influence and significance of various factors on the strategy selection of the government, ESCOs, banks, and existing building owners, according to the known conditions in the hypothesis, MATLAB is used to conduct numerical simulation of the game system to simulate the dynamic evolution process of each participants' behavior.

\section{Conflicts of Interest}

The authors declare that they have no conflicts of interest.

\section{References}

[1] K. H. Kim, S. S. Jeon, A. Irakoze, and K. Y. Son, "A study of the green building benefits in apartment buildings according to real estate prices: case of non-capital areas in South Korea," Sustainability, vol. 12, no. 6, Article ID 2206, 2020.

[2] T. Huo, H. Ren, and W. Cai, "Estimating urban residential building-related energy consumption and energy intensity in China based on improved building stock turnover model," Science of the Total Environment, vol. 650, pp. 427-437, 2019. 
[3] J. H. Ma, Y. M. Hou, Z. X. Wang, and W. H. Yang, "Pricing strategy and coordination of automobile manufacturers based on government intervention and carbon emission reduction," Energy Policy, vol. 148, Article ID 111919, 2021.

[4] J. H. Ma, Y. M. Hou, W. H. Yang, and Y. Tian, "A time-based pricing game in a compet-itive vehicle market regarding the intervention of carbon emission reduction," Energy Policy, vol. 142, Article ID 111440, 2020.

[5] U. Ali, M. H. Shamsi, M. C. Hoare, K. Purcell, E. Mangina, and J. O'Donnell, "A data-driven approach to optimize urban scale energy retrofit decisions for residential buildings," Applied Energy, vol. 267, Article ID 114861, 2020.

[6] Z. Ma, P. Cooper, D. Daly, and L. Ledo, "Existing building retrofits: methodology and state-of-the-art," Energy and Buildings, vol. 55, pp. 889-902, 2012.

[7] G. Liu, X. H. Li, Y. T. Tan, and G. M. Zhang, "Building green retrofit in China: policies, barriers and recommendations," Energy Policy, vol. 139, Article ID 111356, 2020.

[8] Y. He, N. Liao, J. Bi, and L. Guo, "Investment decision-making optimization of energy efficiency retrofit measures in multiple buildings under financing budgetary restraint," Journal of Cleaner Production, vol. 215, pp. 1078-1094, 2019.

[9] X. Wang, M. Lu, W. Mao, J. Ouyang, B. Zhou, and Y. Yang, "Improving benefit-cost analysis to overcome financing difficulties in promoting energy-efficient renovation of existing residential buildings in China," Applied Energy, vol. 141, pp. 119-130, 2015.

[10] L. He, R. Liu, Z. Zhong, D. Wang, and Y. Xia, "Can green financial development promote renewable energy investment efficiency? A consideration of bank credit," Renewable Energy, vol. 143, pp. 974-984, 2019.

[11] Y. Liu, T. Liu, S. Ye, and Y. Liu, "Cost-benefit analysis for energy efficiency retrofit of existing buildings: a case study in China," Journal of Cleaner Production, vol. 177, pp. 493-506, 2018.

[12] G. Liu, S. Zheng, P. Xu, and T. Zhuang, "An ANP-SWOT approach for ESCOs industry strategies in Chinese building sectors," Renewable and Sustainable Energy Reviews, vol. 93, pp. 90-99, 2018.

[13] M. S. Zhang, Y. Lian, H. Zhao, and C. Xia-Bauer, "Unlocking green financing for building energy retrofit: a survey in the western China," Energy Strategy Reviews, vol. 30, Article ID 100520, 2020.

[14] Q. Gao and J. H. Ma, "Chaos and Hopf bifurcation of a finance system,” Nonlinear Dynamics, vol. 58, no. 1-2, pp. 209-216, 2009.

[15] N. N. Liu, C. Z. Liu, Y. F. Xia, Y. Ren, and J. Z. Liang, "Examining the coordination between green finance and green economy aiming for sustainable development: a case study of China," Sustainability, vol. 12, no. 9, Article ID 3717, 2020.

[16] S. An, B. Li, D. Song, and X. Chen, "Green credit financing versus trade credit financing in a supply chain with carbon emission limits," European Journal of Operational Research, vol. 292, no. 1, pp. 125-142, 2021.

[17] Q. Guo, M. Zhou, N. Liu, and Y. Wang, "Spatial effects of environmental regulation and green credits on green technology innovation under low-carbon economy background conditions," International Journal of Environmental Research and Public Health, vol. 16, no. 17, Article ID 3027, 2019.

[18] W. Yin, Z. Y. Zhu, K. U. Berna, and Y. P. Zhu, "The determinants of green credit and its impact on the performance of Chinese banks," Journal of Cleaner Production, vol. 286, Article ID 124991, 2021.
[19] X. Zhao, Y. T. Tan, L. Y. Shen, G. M. Zhang, and J. H. Wang, "Case-based reasoning approach for supporting building green retrofit decisions," Building and Environment, vol. 160, Article ID 106210, 2019.

[20] E. Bertone, O. Sahin, R. A. Stewart et al., "Role of financial mechanisms for accelerating the rate of water and energy efficiency retrofits in Australian public buildings: hybrid bayesian network and system dynamics modelling approach," Applied Energy, vol. 210, pp. 409-419, 2018.

[21] P. Bertoldi and B. Boza-Kiss, "Analysis of barriers and drivers for the development of the ESCO markets in Europe-ScienceDirect," Energy Policy, vol. 107, pp. 345-355, 2017.

[22] D. Brown, S. Sorrell, and P. Kivimaa, "Worth the risk? An evaluation of alternative finance mechanisms for residential retrofit," Energy Policy, vol. 128, pp. 418-430, 2019.

[23] M. Economidou, P. Zangheri, A. Muller, and L. Kranzl, "Financing the renovation of the cypriot building stock: an assessment of the energy saving potential of different policy scenarios based on the Invert/EE-Lab model," Energies, vol. 11, no. 11, Article ID 3071, 2018.

[24] H. Guo, W. Qiao, and Y. Zheng, "Effectiveness evaluation of financing platform operation of buildings energy saving transformation using ANP-fuzzy in China: an empirical study," Sustainability, vol. 12, no. 7, Article ID 2826, 2020.

[25] X. Liu, Z. Zhang, W. Qi, and D. Wang, "An evolutionary game study of the behavioral management of bid evaluations in reserve auctions," IEEE Access, vol. 8, pp. 95390-95402, 2020.

[26] X. Liang, Y. Peng, and G. Q. Shen, "A game theory based analysis of decision making for green retrofit under different occupancy types," Journal of Cleaner Production, vol. 137, pp. 1300-1312, 2016.

[27] H. M. Liu, X. Y. Zhang, and M. Y. Hu, "Game-theory-based analysis of energy perform-ance contracting for building retrofits," Journal of Cleaner Production, vol. 231, pp. 1089-1099, 2019.

[28] X. Yang, J. Zhang, G. Q. Shen, and Y. Yan, "Incentives for green retrofits: an evolutionary game analysis on PublicPrivate-Partnership reconstruction of buildings," Journal of Cleaner Production, vol. 232, pp. 1076-1092, 2019.

[29] H. Shen, Y. Peng, and C. X. Guo, "Analysis of the evolution game of construction an-d demolition waste recycling behavior based on prospect theory under environmental regulation," International Journal of Environmental Research and Public Health, vol. 15, no. 7, Article ID 1518, 2018.

[30] Y. Liu, D. Cai, C. X. Guo, and H. Z. Huang, "Evolutionary game of government subsidy strategy for prefabricated buildings based on prospect theory," Mathematical Problems in Engineering, vol. 2020, Article ID 8863563, , 2020.

[31] X. R. Yu, G. L. Dong, and C. Y. Liu, "The tripartite regulation game of carbon financial products based on the prospect theory," Frontiers in Environmental Science, vol. 8, Article ID 610732, 2020.

[32] B. Bao, J. Ma, and M. Goh, "Short- and long-term repeated game behaviours of two parallel supply chains based on government subsidy in the vehicle market," International Journal of Production Research, vol. 58, no. 24, pp. 7507-7530, 2020.

[33] W. Lou and J. Ma, "Complexity of sales effort and carbon emission reduction effort in a two-parallel household appliance supply chain model," Applied Mathematical Modelling, vol. 64, pp. 398-425, 2018.

[34] J. Ma and H. Ren, "Influence of government regulation on the stability of dualchannel recycling model based on customer expectation," Nonlinear Dynamics, vol. 94, no. 3, pp. 1775-1790, 2018. 
[35] J. Ma and L. Xie, "The comparison and complex analysis on dual-channel supply chain under different channel power structures and uncertain demand," Nonlinear Dynamics, vol. 83, no. 3, pp. 1379-1393, 2016.

[36] L. Xie, J. Ma, and M. Goh, "Supply chain coordination in the presence of uncertain yield and demand," International Journal of Production Research, pp. 1-17, 2020.

[37] T. Xu and J. Ma, "Feed-in tariff or tax-rebate regulation? Dynamic decision mod-el for the solar photovoltaic supply chain," Applied Mathematical Modelling, vol. 89, pp. 1106$1123,2021$.

[38] M. Achtnicht and R. Madlener, "Factors influencing German house owners' preferences on energy retrofits," Energy Policy, vol. 68, pp. 254-263, 2014.

[39] X. Liang, G. Shen, and L. Guo, "Improving management of green retrofits from a stakeholder perspective: a case study in China," International Journal of Environmental Research and Public Health, vol. 12, no. 11, pp. 13823-13842, 2015.

[40] L. Jia, Q. K. Qian, F. Meijer, and H. Visscher, "Stakeholders' risk perception: a perspective for proactive risk management in residential building energy retrofits in China," Sustainability, vol. 12, no. 7, Article ID 2832, 2020. 